\title{
PROLONGED JOB STRAIN REDUCES TIME-DOMAIN HEART RATE VARIABILITY ON BOTH WORKING AND RESTING DAYS AMONG CARDIOVASCULAR-SUSCEPTIBLE NURSES
}

\author{
ROSSANA BORCHINI ${ }^{1,2}$, MARCO M. FERRARIO ${ }^{1,2}$, LORENZA BERTUั ${ }^{1}$, GIOVANNI VERONESI ${ }^{1}$, \\ MATTEO BONZINI ${ }^{1,2}$, MARCO DORSO $^{3}$, and GIANCARLO CESANA ${ }^{3}$
}

${ }^{1}$ University of Insubria, Varese, Italy

Research Centre in Epidemiology and Preventive Medicine (EPIMED)

Department of Clinical and Experimental Medicine

${ }^{2}$ Occupational and Preventive Medicine Units, Varese, Italy

Ospedale di Circolo-Fondazione Macchi

${ }^{3}$ University of Milano-Bicocca, Monza, Italy

Research Centre in Public Health

\begin{abstract}
Objectives: Modifications of hearth rate variability (HRV) constitute a marker of the autonomic nervous system (ANS) deregulation, a promising pathway linking job strain (JS) and cardiovascular diseases (CVD). The study objective is to assess whether exposures to recent and prolonged JS reduce time-domain HRV parameters on working days (WD) among CVD-susceptible nurses and whether the association also persists on resting days (RD). Material and Methods: 313 healthy nurses were investigated twice with one year interval to assess JS based on the demand-control and the effort-reward models. 36, 9 and 16 CVD-susceptible nurses were classified as low JS in both surveys (stable low strain - SLS), recent high JS (high JS at the second screening only-RHS) and prolonged high JS (high strain in both surveys-PHS), respectively. In 9, 7 and 10 of them, free from comorbidities/treatments interfering with HRV, two 24-h ECG recordings were performed on WD and RD. Differences in the time domain HRV metrics among JS categories were assessed using ANCOVA, adjusted for age and smoking. Results: In the entire sample (mean age: 39 years, 83\% females) the prevalence of high job strain was $38.7 \%$ in the second survey. SDNN (standard deviation of all normal RR intervals) on WD significantly declined among JS categories $(\mathrm{p}=0.02$ ), with geometric mean values of $169.1,145.3$ and $128.9 \mathrm{~ms}$ in SLS, RHS, PHS, respectively. In the PHS group, SDNN remained lower on RD as compared to the low strain subjects (142.4 vs. $171.1 \mathrm{~ms}, \mathrm{p}=0.02$ ). Similar findings were found for the SDNN Index, while SDANN (standard deviation of average RR intervals in all 5 min segments of registration) mean values reduced in the PHS group during WD only. Conclusions: Our findings suggest that persistent JS lowers HRV time-domain parameters, supporting the hypothesis that the ANS disorders may play an intermediate role in the relationship between work stress and CVD.
\end{abstract}

Key words:

Nurses, Job strain, Heart rate variability, HRV, Time-domain parameters, ECG-monitoring

The paper was presented at the 6th ICOH International Conference on Work Environment and Cardiovascular Diseases; 2013 Mar 27-30; Tokyo, Japan. The present study was supported in part by grant from the Health Administration of Regione Lombardia (grant No. 10800/2009), as part of the Osservatorio Epidemiologico Cardiovascolare Regionale Lombardo-Progetto CAMUNI.

Received: January 22, 2014. Accepted: March 27, 2014.

Corresponding author: M.M. Ferrario, University of Insubria at Varese, Research Centre in Epidemiology and Preventive Medicine (EPIMED), Department of Clinical and Experimental Medicine, Via O Rossi 9 - Pad Rossi - 1 piano, 21100 Varese, Italy (e-mail: marco.ferrario@uninsubria.it). 


\section{INTRODUCTION}

Job strain (JS) in many studies has been found to be associated with an increased risk for coronary heart diseases [1]. A recently published pooled analysis of prospective cohort studies estimated an overall hazard ratio of 1.23 for high job strain versus no job strain [2]. An earlier meta-analysis reported higher relative risks when JS was assessed through the Effort-Reward Imbalance (ERI) model [3]. Two pathways have been advocated to explain the relationship between psychological stress and the cardiovascular system: the hypothalamic-pituitary-adrenal axis and the autonomic nervous system [4]. Heart rate variability (HRV), which represents variations in normal RR intervals, is recognized as a valuable quantitative marker of cardiac autonomic dysfunction [5]. Several studies established that a reduced HRV is a strong and independent predictor of mortality in patients with cardiovascular diseases, and of cardiovascular events in healthy subjects [5-8]. Moreover, a temporary reduction in HRV has been reported in subjects undergoing acute mental stress $[9,10]$. Lucini et al. have found an association between autonomic dysfunction and real-life stress conditions [11], and other studies have explored associations between HRV modifications and job strain adopting the demand-control or Effort-Reward Imbalance (ERI) models [12,13].

Studies registering ECG for short durations (5 or $10 \mathrm{~min}$ ) reported reductions of the standard deviation of the $\mathrm{NN}$ interval (SDNN) during working periods in high strain workers [14-16]. Among the studies adopting long-ECG recordings ( $24 \mathrm{~h}$ or more) reductions of time-domain HRV parameters in high JS subjects during working days (WDs) have been reported by many authors [12,17-21], but only one study found some effects of job strain on resting days (RDs) in exhausted subjects [18].

As reported by many studies, positive family histories of cardiovascular or metabolic diseases have influence on HRV. Piccirillo et al. [22] have found a lower vagal tone in the offspring of hypertensive patients compared to those without a family story of hypertension, and Mavel et al. [23] have reported similar findings in normotensive subjects with family story of hypertension. A reduction in HRV was also reported among healthy subjects with positive family history of diabetes [24,25] or premature heart attack and sudden death [26]. Genetic susceptibility to cardiovascular diseases (CVD) [27] has been considered when a positive history of any of the mentioned above disorders was determined.

The aims of the present study are:

1. To assess differences between time-domain HRV parameters during $\mathrm{WD}$, in 3 groups of CVD-susceptible healthy nurses characterized by stable low strain, recent and prolonged (lasting at least one year) high job strain.

2. To assess whether such differences extend to RD, supporting the theory of persistent effects of job strain on the cardiovascular system.

\section{MATERIAL AND METHODS}

\section{Study population}

Nurses and nurse assistants working for at least one year in medical and surgical wards of a Northern Italian university hospital were asked to participate in a survey concerning working conditions and job strain. The survey took place in February 2010, and 398 out of 518 nurses (participation rate 76\%) filled in a structured questionnaire to ascertain the perceived working conditions, including items on the demand-control and effort-reward aspects. The same survey was repeated one year later on the same subjects, and 313 nurses (participation 78.6\%) filled in the second questionnaire. The surveys were carried out in collaboration with the employee health representatives, who actively endorsed and recommended participation. All the recruited subjects signed an informed consent and the study was approved by the local hospital ethical committee. 


\section{Job strain assessment}

Both the Job Content Questionnaire (JCQ) [28,29] and the Effort-Reward Imbalance (ERI) questionnaire [30] were adopted to identify high strain subjects. In each survey, we defined a "high strain" category when either psychological job demand (PJD) was above the second tertile value ( $>38$, in our population) and decision latitude (DL) below the 1st tertile $(<66)$; or when the effort to reward ratio (ERI ratio) was above the second tertile (1.21). Similarly, "low strain" subjects were identified when either PJD was below the first $(<34)$ and DL above the second $(>70)$ tertiles, or when the ERI ratio resulted below the first tertile $(<0.40)$. Nurses with strain scores not included in these categories were classified into a single intermediate job strain category.

A 3-level study exposure variable was defined by combining the results of the 2 surveys, as follows. The subjects who reported high strain $(\mathrm{N}=29)$ and low strain $(\mathrm{N}=52)$ in both surveys were defined as prolonged high strain (PHS) and stable low strain (SLS), respectively. Finally, 17 nurses in the intermediate job strain category in the first survey and with high strain in the second survey, were classified as a category called recently high strain (RHS).

\section{Inclusion and exclusion criteria}

All the nurses were carefully investigated with regard to family history of coronary heart diseases, hypertension and diabetes mellitus occurring in the first-degree relatives. Only the people with at least one positive family history of any of these diseases were then included into the study. CVD-susceptible nurses resulted to be 16, 9 and 36 in the PHS, RHS and SLS groups, respectively.

Moreover, 3 and 9 nurses in the PHS and SLS groups, respectively, were excluded from the study due to affected hypertension, diabetes, neurological or endocrinal disorders, or due to drug treatments with antihypertensive, antiarrhythmic, neuroleptic and antidepressant medications, which are known to have effects on the autonomic nervous system. Of eligible nurses, 10, 7 and 19 gave their written consent to undergo 24-hour ECG monitoring in the PHS, RHS and SLS groups, respectively. None of the female nurses was pregnant or breast-feeding and nobody declared an excessive alcohol consumption or use of illicit drugs.

\section{ECG monitoring and HRV analysis}

Two 24-h ECG monitoring sessions (H-Scribe Mortara) on a WD and on a RD were registered for all the enrolled subjects. The selected WD was at least $72 \mathrm{~h}$ after a night shift to reduce the effect of sleep deprivation. All the subjects were instructed to fill in a diary, indicating the starting and ending times of each relevant activity (i.e., work, sleep, meals, rest, light physical activity) which occurred during ECG recordings. Twelve leads were used in order to detect rate and location of any abnormal repolarization better [31]. ECG segments with anomalies, artifacts or ectopic beats were excluded from the HRV assessment, which was carried out by a single cardiologist. Raw ECG data were processed according to the current standard guidelines [5]. Time domain parameters were assessed on ECG recordings with $>90 \%$ of qualified sinus beats for at least a 23-h periods, otherwise the ECG monitoring was repeated (2 subjects). All the subjects were on sinus rhythm and none evidenced supraventricular or ventricular arrhythmias, conduction abnormalities or signs of ischemia.

\section{Statistical analysis}

The following statistical metrics were computed: SDNN, standard deviation of the average of $\mathrm{NN}$ intervals in 5-min segments (SDANN), the mean of the 5-min standard deviation of the NN interval (SDNN_Index). SDANN and SDNN_Index estimate HR changes due to longer and shorter than 5 min cycles, respectively. The square root of the mean squared differences of successive NN intervals (rMSSD) and the proportion derived by dividing NN50 
by the total number of $\mathrm{NN}$ intervals (pNN50) were also calculated.

Differences of demographic, clinical and psychological characteristics among job strain exposure categories were tested using the ANOVA for quantitative variables and the $\mathrm{Chi}^{2}$ test for qualitative variables. In order to reduce the influence of extreme values, HRV parameters were logtransformed (natural logarithm), and we reported the geometric mean. Differences in HRV ln-transformed measures among strain categories were tested using ANCOVA adjusting for major covariates (age and smoking status), and pair-wise comparisons were used to test differences between the strain categories ( $\mathrm{p}$-values adjusted for multiple comparison according to Tukey). A 2-sided $\alpha$ equal to 0.05 was the level of significance for all statistical tests. Statistical analyses were performed with SAS version 9.2 (SAS Institute, Inc., Cary, NC).

\section{RESULTS}

Among the 313 nurses who participated in both surveys, the percentage of high strain based on JCQ adopting the quadrant term (DL below the median 68 and PJD above the median 34 ) was $25.2 \%$ in the first, and $22.7 \%$ in the second survey, respectively. According to the ERI strain definition (effort-reward ratio $>1$ ), the percentage of high strain was $18.5 \%$ and $25.2 \%$, in the first, and second survey, respectively. It is interesting to note that only $10 \%$ in each survey were defined as high strain by both definitions, and the prevalence of high strain according to either the JCQ definition or the ERI definition were $32.9 \%$ in the 1 st survey and $38.7 \%$ in the 2 nd.

The enrolled sample was characterized by a high proportion of women (83.3\%), a mean age of 39 years and an average job tenure of 11 years. $72.2 \%$ of them were professional nurses. The subjects were slim (mean BMI of 24) and $30.6 \%$ of them were smokers. Positive family histories of diabetes, ischemic heart disease and hypertension were present in $42 \%, 48 \%$ and $65 \%$ of the subjects, respectively. We observed no statistically significant differences among job strain categories in demographic and clinical characteristics, with the exception of the proportion of current cigarette smokers $(\mathrm{p}=0.03)$ with a higher prevalence in the PHS group (Table 1).

Associations between major covariates (age, gender and smoke) and HRV parameters were explored. As expected, most of the time domain parameters decreased with aging both on working and resting days. Smokers evidenced reduced SDNN_Index on WD $(p=0.012)$ and RD ( $\mathrm{p}=0.018$ ) and pNN50 (in RDs only $\mathrm{p}=0.013$ ). Due to the high prevalence of females in the sample (83.3\%) the expected association between HRV parameters and gender was not tested. The subsequent analyses of HRV measures were then adjusted for age and smoking. Table 2 shows statistically significant differences in most ERI and JCQ constructs and scores (second survey assessment), across the strain categories. Progressive increments of effort and over commitment from the low to recent and prolonged strain categories. Decision latitude means were higher in both, the recent and prolonged strain categories in comparison with the low strain, and an opposite pattern was found for psychological job demand. No statistically significant differences were found in supervisor and coworker support mean values. Based on these data, there is a tendency of JCQ to pick up current conditions of job strain, while ERI seems to be able to better characterize lasting strain situations with a progressive gradient from low to recent and prolonged strain conditions. As reported in Table 3, the analysis of time domain HRV metrics showed significant differences among strain categories $(\mathrm{F}=4.51, \mathrm{p}=0.02)$ for SDNN on working days, with reducing geometric mean values of $169.1 \mathrm{~ms}, 145.3 \mathrm{~ms}$ and $128.9 \mathrm{~ms}$ in SLS, RHS and PHS groups respectively. On resting days the same pattern of SDNN geometric means was observed, but the gradient between RHS and PHS groups was reduced (158.9 ms and $142.4 \mathrm{ms,}$ 
Table 1. Demographic and clinical characteristics in the investigated strain categories from Job Content Questionnaire (JCQ)

\begin{tabular}{|c|c|c|c|c|}
\hline \multirow[b]{2}{*}{ Variable } & \multicolumn{3}{|c|}{ Job Content Questionnaire } & \multirow[b]{2}{*}{$\mathrm{p}$} \\
\hline & $\begin{array}{c}\text { SLS } \\
(\mathrm{N}=19)\end{array}$ & $\begin{array}{c}\text { RHS } \\
(\mathrm{N}=7)\end{array}$ & $\begin{array}{c}\text { PHS } \\
(\mathrm{N}=10)\end{array}$ & \\
\hline Age (years) $(\mathrm{M} \pm \mathrm{SE})$ & $37.3 \pm 1.9$ & $40.3 \pm 2.8$ & $41.0 \pm 4.1$ & $0.58^{*}$ \\
\hline Female $[\mathrm{n}(\%)]$ & $15(79.0)$ & $6(85.7)$ & $9(90.0)$ & $0.74 * *$ \\
\hline Professional nurses [n (\%)] & $16(84.2)$ & $4(57.1)$ & $6(60.0)$ & $0.23^{* *}$ \\
\hline Bachelor degree $[\mathrm{n}(\%)]$ & $7(36.8)$ & $2(28.6)$ & $2(20.0)$ & $0.64^{* *}$ \\
\hline Seniority (years) $(\mathrm{M} \pm \mathrm{SE})$ & $10.2 \pm 2.1$ & $7.1 \pm 1.3$ & $13.7 \pm 4.2$ & $0.40^{*}$ \\
\hline Positive family history of diabetes [n (\%)] & $9(47.4)$ & $3(42.9)$ & $4(40.0)$ & $0.93^{* *}$ \\
\hline Positive family history of hypertension [ $\mathrm{n}(\%)]$ & $14(73.7)$ & $2(28.6)$ & $8(80.0)$ & $0.06^{* *}$ \\
\hline Positive family history of CHD [n (\%)] & $10(52.6)$ & $3(42.9)$ & $4(40.0)$ & $0.78^{* *}$ \\
\hline Body mass index $(\mathrm{M} \pm \mathrm{SE})$ & $24.4 \pm 0.8$ & $25.4 \pm 1.8$ & $22.1 \pm 1.1$ & $0.18^{*}$ \\
\hline Current cigarette smokers [n (\%)] & $5(26.3)$ & $0(0.0)$ & $6(60.0)$ & $0.03^{* *}$ \\
\hline
\end{tabular}

M - mean; SE - standard error.

SLS - stable low strain; RHS - recently high strain; PHS - prolonged high strain.

* F-test from ANOVA.

** Chi ${ }^{2}$ test.

Table 2. Mean (M) and standard deviation (SD) of Effort-Reward Imbalance ratio (ERI) and Job Content Questionnaire (JCQ) according to the job strain category

\begin{tabular}{|c|c|c|c|c|}
\hline \multirow{2}{*}{ Variable } & \multicolumn{3}{|c|}{$\begin{array}{c}\text { Job Content Questionnaire } \\
\qquad(\mathrm{M} \pm \mathrm{SD})\end{array}$} & \multirow{2}{*}{$\mathrm{p}^{*}$} \\
\hline & $\begin{array}{c}\text { SLS } \\
(\mathrm{N}=19)\end{array}$ & $\begin{array}{l}\text { RHS } \\
(\mathrm{N}=7)\end{array}$ & $\begin{array}{c}\text { PHS } \\
(\mathrm{N}=10)\end{array}$ & \\
\hline Effort & $12.8 \pm 4.6$ & $20.4 \pm 2.2$ & $23.6 \pm 4.8$ & $<0.0001$ \\
\hline Reward & $48.7 \pm 5.6$ & $35.6 \pm 9.5$ & $29.8 \pm 11.7$ & 0.0003 \\
\hline Effort-Reward Imbalance ratio & $0.5 \pm 0.2$ & $1.1 \pm 0.4$ & $1.7 \pm 0.62$ & $<0.0001$ \\
\hline Decision latitude & $71.9 \pm 6.3$ & $58.6 \pm 7.3$ & $57.4 \pm 11.4$ & 0.0004 \\
\hline Psychological job demand & $31.2 \pm 2.6$ & $39.3 \pm 2.1$ & $39.1 \pm 5.6$ & $<0.0001$ \\
\hline Supervisor support & $11.3 \pm 2.5$ & $10.3 \pm 1.3$ & $8.1 \pm 3.2$ & 0.1541 \\
\hline Coworker support & $11.4 \pm 1.7$ & $10.6 \pm 1.6$ & $10.1 \pm 2.9$ & 0.0866 \\
\hline
\end{tabular}

SD - standard deviation. Other abbreviations as in Table 1.

* as in Table 1.

respectively), resulting in a borderline statistically significant association $(\mathrm{F}=2.75, \mathrm{p}=0.08)$. When the pair-wise comparisons were tested, statistically significant differences were found for SDNN means between the prolonged and low strain subjects, both on working $(\mathrm{p}<0.01)$ and resting days $(p=0.02)$.
Similar findings have been found for geometric means for SDNN_Index, with significant differences on working days (geometric means: $70.4 \mathrm{~ms}, 59.5 \mathrm{~ms}$ and $54.8 \mathrm{~ms}$, $\mathrm{F}=3.65$ and $\mathrm{p}=0.04)$ and borderline significance on resting days ( $71.9 \mathrm{~ms}, 69.2 \mathrm{~ms}$, and $56.5 \mathrm{~ms}, \mathrm{~F}=2.97$ and $\mathrm{p}=0.07)$ in SLS, RHS and PHS, respectively. Also for 
Table 3. Age- and smoking-adjusted geometric means (M) of time-domain HRV parameters according to the job strain category

\begin{tabular}{|c|c|c|c|c|}
\hline \multirow{2}{*}{$\begin{array}{l}\text { HRV time domain } \\
\text { parameter }\end{array}$} & \multicolumn{3}{|c|}{$\begin{array}{c}\text { Job Content Questionnaire } \\
\qquad(\mathrm{M} \pm \mathrm{SE})\end{array}$} & \multirow{2}{*}{$\mathrm{p}^{*}$} \\
\hline & $\begin{array}{c}\text { SLS } \\
(\mathrm{N}=19)\end{array}$ & $\begin{array}{l}\text { RHS } \\
(\mathrm{N}=7)\end{array}$ & $\begin{array}{c}\text { PHS } \\
(\mathrm{N}=10)\end{array}$ & \\
\hline \multicolumn{5}{|l|}{ SDNN (ms) } \\
\hline WD & $169.1 \pm 9.3$ & $145.3 \pm 13.2$ & $128.3 \pm 9.7$ & 0.0185 \\
\hline $\mathrm{RD}$ & $171.1 \pm 7.9$ & $158.9 \pm 12.0$ & $142.4 \pm 9.0$ & 0.0786 \\
\hline \multicolumn{5}{|l|}{ SDNN_Index (ms) } \\
\hline WD & $70.4 \pm 4.0$ & $59.5 \pm 5.6$ & $54.8 \pm 4.3$ & 0.0370 \\
\hline $\mathrm{RD}$ & $71.9 \pm 4.2$ & $69.2 \pm 6.7$ & $56.5 \pm 4.6$ & 0.0654 \\
\hline \multicolumn{5}{|l|}{ SDANN (ms) } \\
\hline WD & $148.1 \pm 8.9$ & $131.8 \pm 13.1$ & $116.5 \pm 9.7$ & 0.0760 \\
\hline $\mathrm{RD}$ & $144.0 \pm 6.9$ & $133.1 \pm 10.5$ & $125.2 \pm 8.2$ & 0.2298 \\
\hline \multicolumn{5}{|l|}{ RMSSD (ms) } \\
\hline WD & $48.8 \pm 6.2$ & $46.8 \pm 9.8$ & $37.0 \pm 6.5$ & 0.4418 \\
\hline $\mathrm{RD}$ & $52.2 \pm 6.5$ & $66.1 \pm 13.6$ & $40.6 \pm 7.0$ & 0.2010 \\
\hline \multicolumn{5}{|l|}{ PNN50 (\%) } \\
\hline WD & $9.7 \pm 2.4$ & $4.9 \pm 2.0$ & $4.6 \pm 1.6$ & 0.1544 \\
\hline $\mathrm{RD}$ & $11.1 \pm 2.7$ & $8.5 \pm 3.4$ & $4.9 \pm 1.6$ & 0.1570 \\
\hline \multicolumn{5}{|l|}{ HR (bpm) } \\
\hline WD & $76.3 \pm 1.3$ & $82.4 \pm 2.4$ & $78.3 \pm 1.9$ & 0.0879 \\
\hline $\mathrm{RD}$ & $73.5 \pm 1.3$ & $75.1 \pm 2.1$ & $77.1 \pm 1.8$ & 0.2811 \\
\hline
\end{tabular}

SDNN - the standard deviation of the NN interval; SDNN_Index - mean of the 5-min standard deviation of the NN interval; SDANN - standard deviation of the average of NN intervals in 5-min segments; RMSSD - square root of the mean squared differences of successive NN intervals; PNN50 - proportion derived by dividing NN50 by the total number of NN intervals.

HRV - hearth rate variability; SE - standard error.

WD - working day; RD - resting day.

* F-test from ANCOVA.

this time-domain statistics known to be influenced by shorter cycles, statistically significant differences between the low and prolonged strain groups were observed on working days ( $p=0.01)$ and resting days $(p=0.02)$.

Same pattern, but with smaller differences, was found in the case of SDANN on working days and resting days. Only a reduced mean value was detected in the prolonged strain when compared to the low strain nurses during working days, with geometric mean values of $148.1 \mathrm{~ms}$ vs. $116.5 \mathrm{~ms}$ in SLS and PHS groups $(p=0.02)$. We did not find any other statistically significant differences among strain categories for RMSSD, PNN50 and HR, both on working and resting days (Table 3).

\section{DISCUSSION}

In this study, carried out on 36 CVD-susceptible, healthy, young-adult, predominantly female nurses, investigated for job strain conditions twice with one year interval, we found statistically significant decrements of SDNN, SDNN_Index 
and SDANN in the prolonged high strain subjects compared to the stable low strain subjects during WD. No statistically significant differences were found between the subjects with low strain and those exposed to high strain more recently, but the small sample size of the second group $(\mathrm{N}=7)$ should be acknowledged. Moreover, the decrements of SDNN and SDNN_Index between the stable low strain and prolonged high strain nurses persisted on resting days.

Among studies registering ECG for short durations (5 min or $10 \mathrm{~min}$ ) during working periods [14-16], 2 studies reported reductions of SDNN $[15,16]$ attributable to work stress or job strain. In the Whitehall II study, low job control and a cumulative exposure to job strain were associated with lower SDNN [15]. Kang et al., in a sample of 169 male industrial workers, have shown a statistically significant correlation between high job strain and reduction of SDNN [16]. These results have not been confirmed by a previous Japanese study on healthy, male, white collars, in the case of who job strain was not found to be associated with any alterations of HRV [14]. The heterogeneity of these results is not surprising, since it is known that short-term ECG recording requires well-standardized measurement conditions to assess HRV parameters, hardly obtainable in the case of field studies [5]. Among the studies adopting long-ECG recordings (24 h or more), a reduction in time-domain HRV parameters among the high strain subjects have been reported by most authors [12,17-21], although they were limited to working days only. In a sample of 109 male, white-collar workers working in a computer company, high effort-reward imbalance was found to be associated with lower rMSSD, on working days but not on resting days [12]. Job strain was associated with a reduced SDNN during working days among 135 men and women with diverse job titles [17]. A study in 159 female nurses evidenced lack of association between job strain and HRV on working and on resting days [21], but the authors reported rMSSD only as a measure of time-domain HRV. Clays in a large-scale study of white and blue collars workers showed an association between high work stress and a reduction of pNN50 on WD [19]. Finally, Hernandez-Gaytan, in a sample of 54 male physicia$\mathrm{ns}$, has shown lower values of SDNN registered during WD in subjects characterized by high job strain [20]. Summarizing, results from 3 out of all the previously mentioned studies, which adopted, as we did, 24-h ECG recording support, corroborate our findings showing significant correlation between high job strain and lower values of SDNN [17,18,20], registered during a working day. Even if a direct comparison is not completely appropriate, also 2 studies with the short ECG recording have reported the same results $[15,16]$.

In the context of our study, the findings reported by Collins et al. are more stimulating. They have shown a reduction of SDNN associated with a low decision latitude in a sample of 36 men from a wide range of occupations not only on working days, but also during resting days when the analysis was restricted to the exhausted subjects [18]. We found similar results in a sample of healthy, CVD-susceptible nurses, when perceived high job strain persisted for at least 1 year. This finding represents the more original result of the present study, and supports the hypothesis that a lasting high job strain condition reduces the variability of heart rate, a marker of autonomic cardiac dysregulation, responsible for unfavorable cardiac outcomes.

In fact, the SDNN and the SDNN indices are estimates of an overall HRV, while SDANN measures the long-term components of HRV. These 3 measures represent the balance between sympathetic and para-sympathetic system on cardiac control, and their reduction indicates imbalance of the 2 systems with a relative depression on the para-sympathetic control [5,32].

\section{Strengths of the study}

Firstly, we recruited healthy nurses with a positive family history of cardiovascular or metabolic diseases (hypertension, premature coronary heart disease and sudden death and diabetes), which is a marker of CVD-susceptibility, 
and studies have shown that these people are more prone to have lower vagal tone and HRV decrements [22-26]. Secondly, we carefully selected participants excluding the subjects with disorders of the cardiovascular system, neuroendocrine and psychological or pharmacological treatments, which are known to have effects on the autonomic nervous system, and if not selectively associated with the exposure their inclusion might have contributed to get null results in terms of association between exposure and outcome.

Thirdly, to ascertain job strain we used 2 concurrent, validated questionnaires, i.e. the Job Content Questionnaire (JCQ) and Effort Reward Imbalance (ERI). One study has reported an association of alterations of HRV when using the ERI model only [33].

Additionally, the longitudinal study design with a repeated measure of job strain allowed to separate the effect on HRV between the individuals with recent and persistent high job strain and to compare them with the people reporting stable low job strain, connoting more extreme stress conditions.

Finally, in our study, decrements of time-domain HRV measurements have been found among smokers and among older subjects both on working and on resting days. These findings are supported by similar results in the large majority of previous studies with respect to the former [34-37] and latter [38-40] evidence, and support good external validity of our data.

The major shortcoming of our study is the small sample size, in particular the small number of the subjects in the recently strained group. The reduced statistical power may then be responsible for some borderline statistical significance, and our results need to be replicated on larger samples.

\section{CONCLUSIONS}

The results of our study suggest that persistent job strain lowers HRV time-domain parameters, supporting the hypothesis that the autonomic nervous system disorders may play an intermediate role in the relationship between work stress and CVD.

\section{REFERENCES}

1. Belkic K, Landsbergis P, Schnall P, Baker D, Theorell T, Siegrist J, et al. Psychosocial factors: Review of the empirical data among men. In: Schnall P, Belkic K, Landsbergis P, Baker D, editors. The workplace and cardiovascular disease. Occup Med State Art Rev. 2000;15:24-46.

2. Kivimäki M, Nyberg ST, Batty GD, Fransson EI, Heikkiläet $\mathrm{K}$, Alfredsson L, et al. Job strain as a risk factor for coronary heart disease: A collaborative meta-analysis of individual participant data. Lancet. 2012;380:1491-7, http:// dx.doi.org/10.1016/S0140-6736(12)60994-5.

3. Kivimäki M, Virtanen M, Elovainio M, Kouvonen A, Väänänen A, Vahtera J. Work stress in the aetiology of coronary heart disease - A meta-analysis. Scand J Work Environ Health. 2006;32(6):431-42, http://dx.doi.org/10.5271/ sjweh.1049.

4. Brotman DJ, Golden SH, Wittstein IS. The cardiovascular toll of stress. Lancet. 2007;370:1089-100, http://dx.doi. org/10.1016/S0140-6736(07)61305-1.

5. Task Force of the European Society of Cardiology and the North American Society of Pacing and Electrophysiology. Heart rate variability-standards of measurement, physiological interpretation, and clinical use. Circulation. 1996;93:1043-65, http://dx.doi.org/10.1161/01.CIR. 93.5.1043.

6. Kleiger RE, Miller JP, Bigger JT, Moss AJ. Decreased heart rate-variability and its association with increased mortality after acute myocardial-infarction. Am J Cardiol. 1987; 59:256-62, http://dx.doi.org/10.1016/0002-9149(87)90795-8.

7. Tsuji H, Venditti FJ, Manders ES, Evans JC, Larson MG, Feldman CL, et al. Reduced heart-rate-variability and mortality risk in an elderly cohort-the Framingham heart-study. Circulation. 1994;90:878-83, http://dx.doi.org/10.1161/01. CIR.90.2.878. 
8. Liao DP, Cai JW, Rosamond WD, Barnes RW, Hutchinson RG, Whitsel EA, et al. Cardiac autonomic function and incident coronary heart disease: A population-based casecohort study - The ARIC study. Am J Epidemiol. 1997;145: 696-706, http://dx.doi.org/10.1093/aje/145.8.696.

9. Hall M, Vasko R, Buysse D, Ombao H, Chen QX, Cashmere JD, et al. Acute stress affects heart rate variability during sleep. Psychosom Med. 2004;66:56-62, http://dx.doi. org/10.1097/01.PSY.0000106884.58744.09.

10. Isowa $\mathrm{T}$, Ohira $\mathrm{H}$, Murashima S. Immune, endocrine and cardiovascular responses to controllable and uncontrollable acute stress. Biol Psychol. 2006;71:202-13, http://dx.doi. org/10.1016/j.biopsycho.2005.04.002.

11. Lucini D, Norbiato G, Clerici M, Pagani M. Hemodynamic and autonomic adjustments to real life stress conditions in humans. Hypertension. 2002;39:184-8, http://dx.doi. org/10.1161/hy0102.100784.

12. Vrijkotte TGM, van Doornen LJP, de Geushanno EJC. Effects of work stress on ambulatory blood pressure, heart rate, and heart rate variability. Hypertension. 2000;35: 880-6, http://dx.doi.org/10.1161/01.HYP.35.4.880.

13. Hanson EK, Godaert GL, Maas CJ, Meijman TF. Vagal cardiac control throughout the day: The relative importance of effort-reward imbalance and within-day measurements of mood, demand and satisfaction. Biol Psychol. 2001; 56(1):23-44.

14. Kageyama T, Nishikido N, Kobayashi T, Kurokawa Y, Kaneko T, Kabuto M. Self-reported sleep quality, job stress, and daytime autonomic activities assessed in terms of shortterm heart rate variability among male white-collar workers. Ind Health. 1998;36:263-72, http://dx.doi.org/10.2486/ indhealth.36.263.

15. Chandola T, Britton A, Brunner E, Hemingway H, Malik M, Kumari M, et al. Work stress and coronary heart disease: What are the mechanisms? Eur Heart J. 2008;29(5):640-8, http://dx.doi.org/10.1093/eurheartj/ehm584.

16. Kang MG, Koh SB, Cha BS, Park JK, Woo JM, Chang SJ. Association between job stress on heart rate variability and metabolic syndrome in shipyard male workers. Yonsei Med J. 2004;45(5):838-46.

17. van Amelsvoort LGPM, Schouten EG, Maan AC, Svenne CA, Kok FJ. Occupational determinants of heart rate variability. Int Arch Occup Environ Health. 2000;73: 255-62, http://dx.doi.org/10.1007/s004200050425.

18. Collins S, Karasek R, Costas K. Job strain and autonomic indices of cardiovascular disease. Am J Ind Med. 2005;48: 182-93, http://dx.doi.org/10.1002/ajim.20204.

19. Clays E, de Bacquer D, Crasset V, Kittel F, de Smet P, Kornitzer M, et al. The perception of work stressors is related to reduced parasympathetic activity. Int Arch Occup Environ Health. 2011;84:185-91, http://dx.doi.org/10.1007/ s00420-010-0537-z.

20. Hernandez-Gaytan SI, Rothenberg SJ, Landsbergis P, Peceril LC, de Léon-Léon G, Collins SM, et al. Job strain and heart rate variability in resident physicians within a general hospital. Am J Ind Med. 2012;56(1):38-48, http://dx.doi.org/10.1002/ajim.22098.

21. Riese H, van Doornen LJP, de Geus EJC. Job strain in relation to ambulatory blood pressure, heart rate, and heart rate variability among female nurses. Scan J Work Environ Health. 2004;30(6):477-85, http://dx.doi.org/10.5271/ sjweh.837.

22. Piccirillo G, Viola E, Nocco M, Durante M, Tarantini S, Marigliano V. Autonomic modulation of heart rate and blood pressure in normotensive offspring of hypertensive subjects. J Lab Clin Med. 2000;135:145-52, http://dx.doi. org/10.1067/mlc.2000.103428.

23. Maver J, Strucl M, Accetto R. Autonomic nervous system and microvascular alterations in normotensives with a family history of hypertension. Blood Press. 2004;13:95-100, http://dx.doi.org/10.1080/08037050310031035.

24. de Angelis C, Perelli P, Trezza R, Casagrande M, Biselli R, Pannitteri G, et al. Modified autonomic balance in offsprings of diabetics detected by spectral analysis of heart rate variability. Metabolism. 2001;50(11):1270-4, http://dx.doi.org/ 10.1053/meta.2001.27225. 
25. Lindmark S, Wiklund U, Bjerle P, Eriksson JW. Does the autonomic nervous system play a role in the development of insuline resistance? A study on heart rate variability in first-degree relatives of type 2 diabetes patients and control subjects. Diabet Med. 2003;20:399-405, http://dx.doi. org/10.1046/j.1464-5491.2003.00920.x.

26. Sajadieh A, Rasmussen V, Hein HO, Hansen JF. Familiar predisposition to premature heart attack and reduced heart rate variability. Am J Cardiol. 2003;92:234-6, http://dx.doi. org/10.1016/S0002-9149(03)00548-4.

27. Watkins H, Farrall M. Genetic susceptibility to cardiovascular artery disease: From promise to progress. Nat Rev Gentet. 2006;7(3):163-73, http://dx.doi.org/10.1038/nrg1805.

28. Karasek RA. Job Demands, job decision latitude, and mental strain. Implication for job redesign. Adm Sci Q. 1979;24:285, http://dx.doi.org/10.2307/2392498.

29. Karasek R, Brisson C, Kawakami N, Houtman I, Bongers P, Amick B. The Job Content Questionnaire (JCQ): An instrument for internationally comparative assessments of psychosocial job characteristics. J Occup Health Psychol. 1998;3(4): 322-55, http://dx.doi.org/10.1037/1076-8998.3.4.322.

30. Siegrist J. Adverse health effects of high-effort/low-reward conditions. J Occup Health Psychol. 1996;1(1):27-41, http://dx.doi.org/10.1037/1076-8998.1.1.27.

31. Klootwijk P, Meij S, von Es GA, Müller EJ, Umans VA, Lenderink T, et al. Comparison of usefulness of computer assisted continuous 48-h 3-lead with 12-lead ECG ischaemia monitoring for detection and quantitation of ischaemia in patients with unstable angina. Eur Heart J. 1997;18(6):931-40, http://dx.doi.org/10.1093/oxfordjournals.eurheartj.a015381.

32. Berntson G, Bigger JT, Eckberg DL, Grossman P, Kaufmann PG, Malik M, et al. Heart rate variability: Origins, methods, and interpretive caveats. Psychophysiology. 1997;34(6): 623-48, http://dx.doi.org/10.1111/j.1469-8986.1997.tb02140.x.
33. Loerbrocks A, Schilling O, Haxsen V, Jarczok MN, Thayer JF, Fischer JE. The fruits of ones labor: Effort-reward imbalance but not job strain is related to heart rate variability across the day in 35-44-year-old workers. J Psychosom Res. 2010;69:151-9, http://dx.doi.org/10.1016/j.jpsychores.2010.03.004.

34. Barutcu I, Esen AM, Kaya D, Turkmen M, Karakaya O, Melek M, et al. Cigarette smoking and heart rate variability: Dynamic influence of parasympathetic and sympathetic maneuvers. Ann Noninvas Electrocardiol. 2005;10(3): 324-9, http://dx.doi.org/10.1111/j.1542-474X.2005.00636.x.

35. Hayano J, Yamada M, Sakakibara Y, Fujinami T, Yokoyama K, Watanabe Y, et al. Short, longterm effects of cigarette smoking on heart rate variability. Am J Cardiol. 1990;65: 84-8, http://dx.doi.org/10.1016/0002-9149(90)90030-5.

36. Lucini D, Bertocchi F, Malliani A, Pagani M. A controlled study of the autonomic changes produced by habitual cigarette smoking in healthy subjects. Cardiovasc Res. 1996;31: 633-9, http://dx.doi.org/10.1016/0008-6363(96)00013-2.

37. Niedermaier ON, Smith ML, Beightol LA, Zukowska-Grojec Z, Goldstein DS, Eckberg DL. Influence of cigarette smoking on human autonomic function. Circulation. 1993; 88: 562-71, http://dx.doi.org/10.1161/01.CIR.88.2.562.

38. Acharya UR, Kannathal N, Seng OW, Ping LY, Chua T. Heart rate analysis in normal subjects of various age groups. Biomed Online J. 2004;3(24):1-8, http://dx.doi. org/10.1186\%2F1475-925X-3-24.

39. Rajendra Acharya U, Paul Joseph K, Kannathal N, Lim CM, Suri JS. Heart rate variability: A review. Med Bio Eng Comput. 2006;44:1031-51, http://dx.doi.org/10.1007/s11517-0060119-0.

40. Schwartz JB, Gibb WJ, Tran T. Aging effects on heart rate variation. J Gerontol. 1991;46:M99-M106, http://dx.doi.org/ 10.1093/geronj/46.3.M99.

This work is available in Open Access model and licensed under a Creative Commons Attribution-NonCommercial 3.0 Poland License - http://creativecommons.org/ licenses/by-nc/3.0/pl/deed.en. 